\title{
Foreword to the Special Issue on Food Allergen Methodologies
}

\author{
Samuel Benrejeb Godefroy • Michael Abbott • \\ Terry Koerner • David Rodríguez-Lázaro
}

Received: 17 August 2009/Accepted: 20 August 2009 /Published online: 24 September 2009

(C) Springer Science + Business Media, LLC 2009

Food Allergy is an on-going public health problem and continues to be a challenge to both the clinical community and the food industry. Food safety regulators, industry, and consumer groups are working towards the development of the appropriate risk assessment and risk management procedures to prevent the inadvertent consumption of allergenic ingredients by allergic individuals, while not unduly impairing their choice.

The availability of analytical methods to detect and determine levels of markers of priority allergens in foods are of the utmost importance to support standard setting initiatives, the development of compliance and enforcement activities, as well as to provide guidance to industry on implementation of quality control practices and ensuring the effectiveness of allergen-related sanitation techniques.

\author{
S. B. Godefroy \\ Health Canada, Food Directorate, \\ Sir Frederick Banting Research Centre, \\ Ottawa, Canada \\ e-mail: Samuel_Godefroy@hc-sc.gc.ca \\ M. Abbott $\cdot$ T. Koerner \\ Health Canada, Food Research Division, \\ Sir Frederick Banting Research Centre, \\ Ottawa, Canada \\ M. Abbott \\ e-mail: michael abbott@hc-sc.gc.ca \\ T. Koerner \\ e-mail: terry_koerner@hc-sc.gc.ca \\ D. Rodríguez-Lázaro ( $\square)$ \\ Food Safety and Technology, \\ Instituto Tecnoplógico Agario de Castilla y León (ITACyL), \\ Carretera de Burgos km 119, Valladolid, Spain \\ e-mail: ita-rodlazda@itacyl.es
}

Beginning in October of 2003, Health Canada's Food Directorate has hosted a series of workshops on Food Allergen Methodologies. These workshops aim to gather scientists, chemists, analysts, and other representatives from government agencies, academia, industry, and consumer associations, to discuss issues related to the detection, identification, characterization, and control of allergens in foods. Truly international in scope, these workshops have attracted participation from around the world, including European nations, Australia, Hong Kong, Japan, USA, as well as from all across Canada.

This special issue of food analytical methods is dedicated to reporting on the fifth workshop on food allergen methodologies, which took place in Halifax, Nova Scotia, Canada, from May 11-14, 2008. Health Canada's Food Directorate, along with the Food Allergy Research and Resource Program of the University of Nebraska, USA, coorganized the event with support from $C$ MoniQA (Monitoring and Quality Assurance in the food supply - an international Network of Excellence cofunded by the European Union). The workshop was an opportunity to enhance consultation, information exchange, and to foster harmonization of method validation in the area of food allergens. The event gathered scientists, analysts, and other representatives from government agencies, university, and Food Industry.

This special issue presents some highlights of the workshop which discussed method development for specific food allergens, method validation requirements, international initiatives such as that supported by the MoniQA network of excellence, as well as surveys aiming to determine levels of allergens in correspondence with labeling.

The guest editors of this special issue would like to thank workshop participants and authors for making this workshop a success and for their contribution to this special issue. 